\title{
Vibrational, NMR spectrum and orbital analysis of 3,3',5,5'-tetrabromobisphenol A: A combined experimental and computational study
}

\author{
Shanshan Qiu ${ }^{\mathrm{a}, \mathrm{b}, *}$, Jin Wei $^{\mathrm{c}}$, Feng Pan ${ }^{\mathrm{a}, \mathrm{b}}$, Jingping Liu ${ }^{\mathrm{a}, \mathrm{b}}$, Aiqian Zhang ${ }^{\mathrm{d}}$ \\ ${ }^{a}$ School of Chemical Engineering, Nanjing University of Science and Technology, Nanjing, Jiangsu 210094, PR China \\ ${ }^{\mathrm{b}}$ National Quality Supervision and Inspection Center for Industrial Explosive Materials, Nanjing, Jiangsu 210094, PR China \\ ' Jiangsu Provincial Academy of Environmental Science, Nanjing, Jiangsu 210036, PR China \\ ${ }^{\mathrm{d}}$ State Key Laboratory of Environmental Chemistry and Ecotoxicology, Research Center for Eco-Environmental Sciences, Chinese Academy of Sciences, Beijing 100085, PR China
}

\section{H I G H L I G H T S}

- The calculated structure and vibration correspond well with the experimental data.

- The calculated NMR showed good agreement with the experimental data $\left(r^{2}=0.999\right)$.

- The $\mathrm{p}-\pi$ conjugation between $\mathrm{O}$ and benzene leads to the red shift of $\mathrm{C}-\mathrm{Br}$ vibration.

- The lower $E^{(2)}\left(\mathrm{LP}(3) \mathrm{Br} \rightarrow \pi^{*}(\mathrm{C}-\mathrm{C})\right)$ leads to the preferential tendency of $\mathrm{C}-\mathrm{Br}$ breakage.

- The main excitation by TDDFT exhibit $\pi-\pi^{*}$ character localized on the benzene rings.

\section{A R T I C L E I N F O}

\section{Article history:}

Received 21 May 2012

Received in revised form 30 November 2012

Accepted 3 December 2012

Available online 12 December 2012

\section{Keywords:}

3,3',5,5'-Tetrabromobisphenol A

Density functional theory

Vibrational spectrum

NMR

NBO

Orbital

\section{G R A P H I C A L A B S T R A C T}
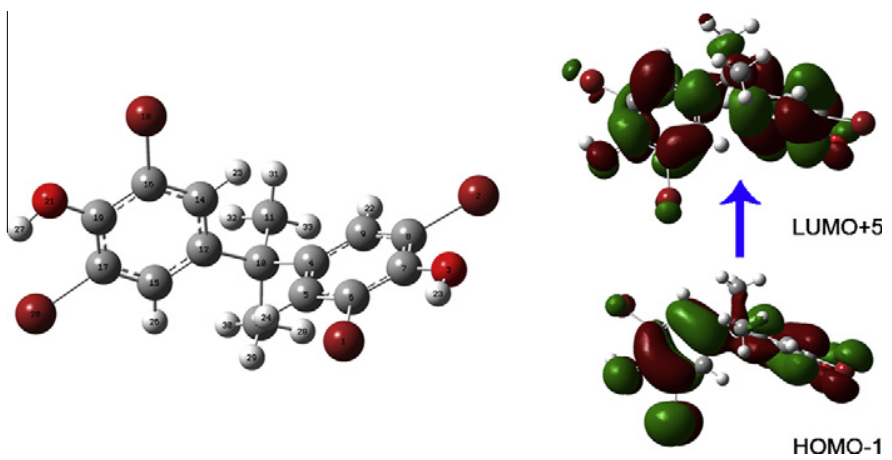

\begin{abstract}
A B S T R A C T
In the present work, the experimental and theoretical studies on the structure, vibrations, NMR and HOMO-LUMO analysis of 3,3',5,5'-tetrabromobisphenol A (TBBPA) are presented. The FT-IR (400$\left.4000 \mathrm{~cm}^{-1}\right)$ and FT-Raman $\left(100-4000 \mathrm{~cm}^{-1}\right)$ spectra of TBBPA were recorded. The molecular geometry, vibrational frequencies were calculated by using density functional theory (DFT) method with the 6$31 \mathrm{G}(\mathrm{d})$ basis set. The optimized geometric properties, scaled vibrational wavenumbers, IR intensities, Raman activities show good agreement with the experimental data. The assigned vibrational modes of the IR and Raman spectra were compared with the corresponding properties of the polybrominated diphenyl ethers (PBDEs). Comparative analysis indicated that the red shift of $\mathrm{C}-\mathrm{Br}$ vibration could probably be ascribed to the further electronic density equalization due to the $p-\pi$ conjugation between $O$ atom and the benzene. The natural bonding orbital (NBO) analysis demonstrated that the intermolecular hyperconjugative interactions are mainly formed by the orbital overlap between $\sigma(\mathrm{O}-\mathrm{H}), \sigma^{*}(\mathrm{C}-\mathrm{C}), \pi(\mathrm{C}-$ C), $\pi^{*}(C-C)$ bond orbitals. Compared to the higher $E^{(2)}$ value $(33.65-34.82 \mathrm{kcal} / \mathrm{mol})$ originated from $\mathrm{LP}(2) \mathrm{O}$ to $\pi^{*}(\mathrm{C}-\mathrm{C})$, the one $\left(E^{(2)}: 8.23-9.73 \mathrm{kcal} / \mathrm{mol}\right)$ from $\mathrm{LP}(3) \mathrm{Br}$ and $\pi^{*}(\mathrm{C}-\mathrm{C})$ contributes to the preferential tendency of $\mathrm{C}-\mathrm{Br}$ breakage to the $\mathrm{C}-\mathrm{O}$ breakage in the transformation. The calculated NMR results obtained on the $6-31 \mathrm{G}(\mathrm{d})$ level proves good agreement with the experimental data $\left(r^{2}=0.999\right)$. Analysis of isosurface of the related orbital shows that all the main excitation exhibit $\pi-\pi^{*}$ character localized on the benzene rings.
\end{abstract}

(c) 2012 Elsevier B.V. All rights reserved.

\footnotetext{
* Corresponding author at: School of Chemical Engineering, Nanjing University of Science and Technology, Nanjing, Jiangsu 210094, PR China. Tel./fax: +86-2584303990.

E-mail address: ppshanshanqiu@gmail.com (S. Qiu).
}

\section{Introduction}

Brominated flame retardants (BFRs) have attracted worldwide concern because of their wide dispersion, high lipophilicity and 
persistence [1]. 3,3',5,5'-tetrabromobisphenol A (TBBPA), one of the most widely used BFRs around the world [2], has been detected in various environmental matrices such as air, dust, wastewater, sediments and aquatic biota [3]. In November 2010, TBBPA has been restricted and banned on the use of in plastic infant feeding bottle by European Commission (EC) due to the potential endocrine disrupting effect [4]. To the best of our knowledge, current studies on TBBPA include the experimental work on the exposure concentration, toxicity and elimination [5-7]. However, theoretical understanding towards the properties of TBBPA is still lacking except thermodynamic property [1] and the establishment of QSAR models [8].

Theoretical and experimental understanding of the structure and vibration is urgently necessary especially for the pure chemicals of limited availability. Previous studies from our laboratory have shown that the number and position of the bromine substituent of typical polyhalogenated compounds such as polybrominated diphenyl ethers (PBDEs) have great influence on their electronic structures $[9,10]$. Chemical structure of TBBPA resembles that of the PBDEs. However, the metabolism mechanisms of the two in environment are quite different. The main objective of this paper is to elucidate difference between TBBPA and PBDEs. To investigate the electronic structure and spectroscopic properties with density functional theory (DFT) method, we identified the effect of the C$\mathrm{O}-\mathrm{C}$ bond or phenolic hydroxyl on the molecular properties. In addition to this, the molecular orbital analysis based on the natural bonding orbital (NBO) analysis was employed to understand the nature of the degradation processes of TBBPA.

\section{Experiments}

The solid TBBPA was purchased from Sigma-Aldrich Company with a stated purity of $97 \%$ and used as such without further purification for the spectral measurements. The FT-IR spectrum of the sample was recorded in the region $400-4000 \mathrm{~cm}^{-1}$ on Nicolet Nexus 870 Spectrophotometer at room temperature. The Raman spectrum of the sample was measured using $514 \mathrm{~nm}$ excitation line of $\mathrm{Ar}^{+}$laser in the frequency region $100-4000 \mathrm{~cm}^{-1}$ on Renishaw invia Raman microscope spectrophotometer. The ${ }^{13} \mathrm{C}$ and ${ }^{1} \mathrm{H}$ NMR spectra were tested in MeOH-d4 on Bruker DPX-300 with tetramethylsilane (TMS) as in internal standard at room temperature.

\section{Computational details}

Evidence accumulated in literature and our previous work on PBDEs $[9,10]$ have proved that the theoretical calculations with DFT method have good performance in the prediction of the structural and vibrational properties of the polyhalogenated compounds.

With the consideration of calculation at the higher level making no significant improvement in the accuracy of the geometrical structure of polyhalogenated compounds $[9,10]$, the method of DFT/B3LYP at the basis level of $6-31 \mathrm{G}(\mathrm{d})$ was adopted to calculate the geometrical parameters and other properties of the title molecule TBBPA in the present work. Actually, the vibrational results calculated on the level of $6-311++G(d, p)$ by our laboratory also showed that the basis of of $6-31 \mathrm{G}(\mathrm{d})$ is sufficient. (The comparison results are presented in Figs. 1 and 2 in Supplementary.) All the calculations were performed using Gaussian 03W program package [11] with the default convergence criteria without any constraint in the potential energy surface.

Detailed assignments of the signals for each vibrational spectrum were made with a high degree of confidence by the results of the Gaussview program [12]. The NBO calculations were performed using NBO 3.1 program as implemented in the Gaussian
03W [11] package. The time-dependant density functional theory (TDDFT) was taken to calculate the vertical excitation energies and oscillator strengths to identify which functional group would preferentially get excited.

NMR Chemical shifts were calculated with the GIAO approach [9]. Absolute isotropic magnetic shielding constants were transformed into chemical shifts $\left(\delta_{i}=\sigma_{T M S}-\sigma_{i}\right)$ by referring to the standard compound TMS.

\section{Results and discussion}

\section{Geometrical structure}

The structure of TBBPA optimized on the basis of B3LYP/6$31 \mathrm{G}(\mathrm{d})$ and the atomic numbering scheme are shown in Fig. 3 in Supplementary. The optimized geometrical parameters are presented in Table 1 and compared with the values in literature [13]. Both rings of TBBPA are planar in the range of 1.387$1.405 \AA(\mathrm{C}-\mathrm{C})$. The substitution of $\mathrm{H}$ with $\mathrm{Br}$ at $\mathrm{C}-\mathrm{H}$ bond results a considerable increase of the bond length. As shown in Table 1, the $\mathrm{C}-\mathrm{Br}$ bond length of TBBPA fall in range 1.904-1.920 $\AA$, similar to those observed in BDE-47 and BDE-15 in our precious studies $[9,10]$. The bond length between the carbon and the oxygen lies at $1.350 \AA$, while the $\mathrm{C}-\mathrm{O}$ ether bond in BDE-47 and BDE-45 are $1.370 \AA[9,10]$. This may be due to the intra-molecular interaction between $O$ and benzene rings. X-ray data [13] exhibit minor stabilization of the structure owing to the intermolecular $\mathrm{O}$. . O contacts, which contributes the shorter distance $0.820 \AA$ of $\mathrm{O}-\mathrm{H}$ than the calculated value $0.975 \AA$ A in this work.

The two benzene rings are joined with $\mathrm{C} 10$ atom and the dihedral angle $\left(A C_{4}-C_{10}-C_{13}-C_{11}, 118.2^{\circ}\right)$ shows the atoms of $C 4, C 10$, $\mathrm{C} 11, \mathrm{C} 12, \mathrm{C} 13$ constitute the typical tetrahedral structure. Another calculated dihedral angle $\left(A C_{14}-C_{12}-C_{10}-C_{4}, 52.9^{\circ}\right)$ is in great agreement with the experimental value $\left(54.9^{\circ}\right)$ [13].

Clearly, the optimized structure with the B3LYP/6-31G(d) method could well reproduce the experimental values. The discrepancy between the calculated and the X-ray data from reference may be due to the fact that molecular packing in crystal structure was excluded in present calculations.

\section{Vibrational spectra}

Comparison of the unscaled calculated frequencies with experimental values reveals the overestimation of the former due to the

Table 1

Calculated geometric parameters of TBBPA by DFT/B3LYP/6-31G(d).

\begin{tabular}{|c|c|c|}
\hline Geometrical parameter & B3LYP/6-31G(d) & $\operatorname{Exp}^{a}$ \\
\hline \multicolumn{3}{|l|}{ Bond length $(\AA)$} \\
\hline$r \mathrm{C}_{6}-\mathrm{Br}_{1}$ & 1.920 & $1.877(7)$ \\
\hline$r \mathrm{C}_{8}-\mathrm{Br}_{2}$ & 1.904 & $1.862(7)$ \\
\hline$r \mathrm{C}_{10}-\mathrm{C}_{4}$ & 1.543 & $1.532(9)$ \\
\hline$r \mathrm{C}_{10}-\mathrm{C}_{11}$ & 1.548 & $1.533(9)$ \\
\hline$r \mathrm{C}_{7}-\mathrm{O}_{3}$ & 1.350 & - \\
\hline $\mathrm{rO}_{3}-\mathrm{H}_{23}$ & 0.975 & - \\
\hline \multicolumn{3}{|l|}{ Bond angle $\left({ }^{\circ}\right)$} \\
\hline$A C_{9}-C_{4}-C_{5}$ & 117.6 & $115.8(7)$ \\
\hline$A C_{14}-C_{12}-C_{10}$ & 119.4 & $123.6(6)$ \\
\hline$A C_{4}-C_{10}-C_{11}$ & 112.2 & $107.9(5)$ \\
\hline$A C_{4}-C_{9}-C_{10}$ & 122.9 & $120.5(6)$ \\
\hline$A_{3}-C_{7}-C_{6}$ & 123.8 & 121.1(8) \\
\hline $\mathrm{AO}_{3}-\mathrm{C}_{7}-\mathrm{C}_{8}$ & 119.7 & 119.6(8) \\
\hline \multicolumn{3}{|l|}{ Dihedral angle $\left(^{\circ}\right)$} \\
\hline$A C_{10}-C_{12}-C_{14}-C_{16}$ & 177.2 & $178.9(7)$ \\
\hline$A C_{4}-C_{10}-C_{13}-C_{11}$ & 118.2 & - \\
\hline$A C_{14}-C_{12}-C_{10}-C_{4}$ & 52.9 & $54.9(9)$ \\
\hline
\end{tabular}

a The experimental data taken from Ref. [14]. 
neglect of the anharmonicity effect in model compound. In order to improve the agreement with the experiment, it is customary to scale down the calculated harmonic frequencies. Consequently, the frequencies of $\mathrm{C}-\mathrm{H}$ and $\mathrm{O}-\mathrm{H}$ stretching vibrations in this study were scaled down by multiplying a factor of $0.958[14,15]$ while other frequencies were scaled down by factors of 0.9613 [16]. The experimental and the scaled stimulated FT-IR and Raman spectra are presented in Figs. 1 and 2. The frequencies for main modes of vibrations are listed in Table 2. It is evident that the scaled frequencies lead to excellent agreement with the observed spectral patterns. No imaginary frequency has been observed at the optimized structure, proving that a true minimum on the potential.

\section{$\mathrm{C}-\mathrm{H}$ and $\mathrm{C}-\mathrm{C}$ vibrations}

Aromatic structure commonly shows multiple weak bands in the region $3000-3100 \mathrm{~cm}^{-1}$, which is the characteristic region for the identification of $\mathrm{C}-\mathrm{H}$ stretching vibrations [17]. The bands in this range are not affected appreciably by the nature of substituents [18]. In the FT-IR spectrum, the frequency $3070 \mathrm{~cm}^{-1}$ was assigned to the $\mathrm{C}-\mathrm{H}$ vibration of benzene. It should be noted that the calculated bands around $2995 \mathrm{~cm}^{-1}$ were ascribed to the $\mathrm{C}-\mathrm{H}$ stretching modes of the methyl groups of TBBPA.

In the substituted benzenes, the $\mathrm{C}-\mathrm{H}$ in-plane and out-of-plane bending vibrations are often coupled and appear in the frequency range $1000-1300 \mathrm{~cm}^{-1}$ [19] and $667-900 \mathrm{~cm}^{-1}$ [20], respectively. In this work, the peaks at $1180 \mathrm{~cm}^{-1}, 1240 \mathrm{~cm}^{-1}, 1320 \mathrm{~cm}^{-1}$ in IR were assigned to $\mathrm{C}-\mathrm{H}$ in-plane bending vibrations. The FT-IR bands at $779 \mathrm{~cm}^{-1}$ and Raman bands at $854 \mathrm{~cm}^{-1}$ confirms the $\mathrm{C}-\mathrm{H}$ outof-plane bending vibrations. As the vibration frequencies owing to para- and ortho-substitution are strongly mixed [18], we were unable to distinguish the modes clearly. The calculated intensities and frequencies due to $\mathrm{C}-\mathrm{H}$ stretching, in-plane and out-of-plane bending vibrations are coinciding very well with the observed frequencies.

Generally, the ring $\mathrm{C}-\mathrm{C}$ stretching vibrations of benzene derivative occur in the region $1400-1650 \mathrm{~cm}^{-1}$ [19]. Present work has shown that the typical bands of this vibration are of variable intensity and observed at $1240 \mathrm{~cm}^{-1}, 1270 \mathrm{~cm}^{-1}, 1320 \mathrm{~cm}^{-1}$, $1400 \mathrm{~cm}^{-1}, 1470 \mathrm{~cm}^{-1}$ in IR spectrum. It should be mentioned here that the IR signal of this vibration mode in TBBPA is similar to the ones of BDE-15 and BDE-47 [9,10]. Nevertheless, only one peak at $1599 \mathrm{~cm}^{-1}$ in Raman with intensive activity was observed and we speculated that the phenol hydroxyl substitution and the higher signal base line lead to the prominent decrease of other relative peaks in recorded spectra. In this work, the IR spectrum assignments for another ring are in good agreement with literature values $[9,10,19]$.

\section{$\mathrm{C}-\mathrm{O}$ and $\mathrm{O}-\mathrm{H}$ vibrations}

Phenols always show characteristic $\mathrm{O}-\mathrm{H}$ stretching band in the region $3200-3650 \mathrm{~cm}^{-1}$ [19]. The prominent IR intensity (101.6) and Raman activity (101.6) of the calculation show good agreement with the experimental observations.

The $\mathrm{C}-\mathrm{O}$ stretching vibration of phenol normally lies in the region of $1200-1300 \mathrm{~cm}^{-1}$ while the $\mathrm{O}-\mathrm{H}$ in-plane bending vibration is often observed near $1260-1420 \mathrm{~cm}^{-1}$. However, as suggested by Balachandran et al. [19], these two vibration modes are usually not independent because they are always coupled with the vibrations of adjacent groups. For TBBPA, the frequencies at $1270 \mathrm{~cm}^{-1}$ (IR) and $1280 \mathrm{~cm}^{-1}$ (Raman) demonstrated interaction between the $\mathrm{C}-\mathrm{O}$ and the $\mathrm{C}-\mathrm{C}$ stretching vibration. The $\mathrm{O}-\mathrm{H}$ in-plane bending and the ring skeleton vibration jointly produced bands near $1240 \mathrm{~cm}^{-1}$ and $1400 \mathrm{~cm}^{-1}$ with moderate intensity in IR spectrum.

\section{C-Br vibrations}

As Balachandran et al. reported [19], the C-X stretching mode has red shift relative to the one in the $\mathrm{C}-\mathrm{H}$ bond. The reason is because of the decreased force constant and increased the reduced mass arising from the inductive effect of the halogen atom. Mooney et al. assigned vibrations of $\mathrm{C}-\mathrm{X}(\mathrm{X}=\mathrm{Cl}, \mathrm{Br}, \mathrm{I})$ in the wide frequency range of $480-1129 \mathrm{~cm}^{-1}[21,22]$. Compared to the $\mathrm{C}-\mathrm{Br}$ vibrational modes for BDE-47 $\left(348 \mathrm{~cm}^{-1}, 313 \mathrm{~cm}^{-1}\right.$, and $\left.275 \mathrm{~cm}^{-1}\right)$
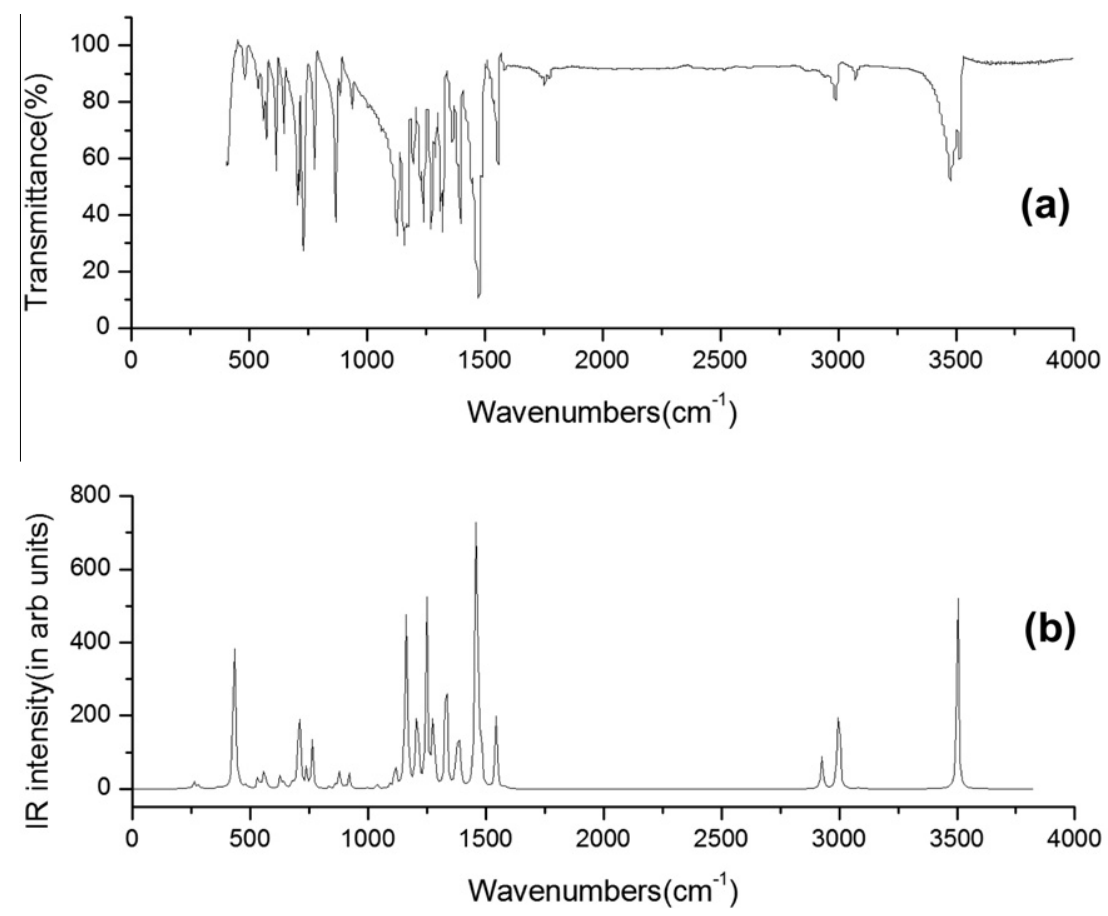

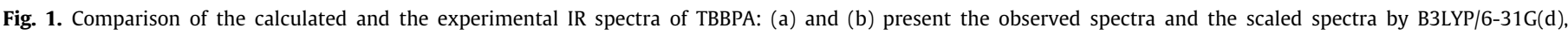
respectively. 

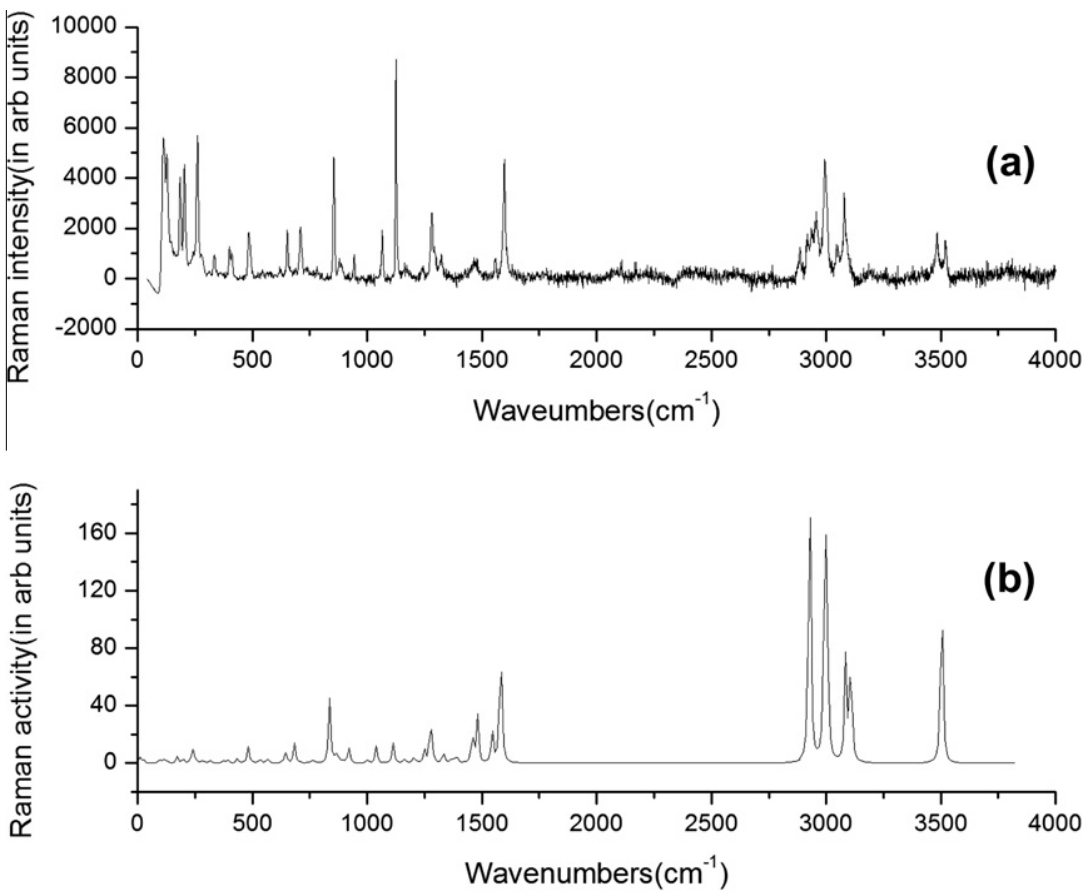

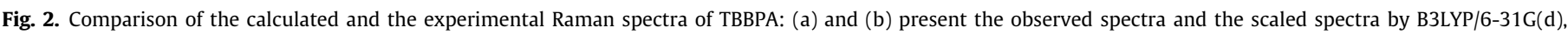
respectively.

Table 2

Comparison of the main calculated vibrational frequencies and experimental (FT-IR and Raman) spectra of TBBPA.

\begin{tabular}{|c|c|c|c|c|c|c|c|}
\hline \multirow[t]{2}{*}{ No. } & \multirow[t]{2}{*}{ Approximate assignments ${ }^{\mathrm{a}}$} & \multicolumn{2}{|c|}{ Experimental freq. ${ }^{\mathrm{b}}$} & \multicolumn{4}{|c|}{ Calculated freq. ${ }^{\mathrm{c}}$} \\
\hline & & IR & Raman & Unscaled & Scaled & $\mathrm{I}(\mathrm{IR})$ & $S(R)$ \\
\hline 1 & $v \mathrm{O}-\mathrm{H}$ & $3510 \mathrm{~m}$ & $3483 \mathrm{~m}$ & 3657 & 3503 & 101.6 & 82.7 \\
\hline 2 & $v \mathrm{C}-\mathrm{H}$ & $3070 \mathrm{sh}$ & 3079 vs & 3222 & 3087 & 0.5 & 41.9 \\
\hline 3 & $v \mathrm{C}-\mathrm{H}$ & $2990 \mathrm{~m}$ & $2993 \mathrm{~m}$ & 3125 & 2994 & 49.5 & 101.1 \\
\hline 4 & $v \mathrm{C}-\mathrm{H}$ & - & $2957 \mathrm{~m}$ & 3057 & 2928 & 18.3 & 213.3 \\
\hline 5 & $v \mathrm{C}-\mathrm{C}$ & - & $1599 \mathrm{~ms}$ & 1647 & 1583 & 0.8 & 68.6 \\
\hline 6 & $\gamma \mathrm{C}-\mathrm{C}, v \mathrm{C}-\mathrm{H}$ & 1470 vs & - & 1515 & 1456 & 111.1 & 11.1 \\
\hline 7 & $v \mathrm{C}-\mathrm{C}, \beta \mathrm{O}-\mathrm{H}$ & $1400 \mathrm{~m}$ & - & 1442 & 1386 & 28.2 & 0.5 \\
\hline 8 & $v \mathrm{C}-\mathrm{C}, \beta \mathrm{C}-\mathrm{H}$ & $1320 \mathrm{~s}$ & - & 1384 & 1330 & 85.1 & 3.9 \\
\hline 9 & $\nu \mathrm{C}-\mathrm{C}, \beta \mathrm{C}-\mathrm{H}, \beta \mathrm{O}-\mathrm{H}$ & 1240 vs & - & 1300 & 1250 & 104.0 & 6.0 \\
\hline 10 & $v \mathrm{C}-\mathrm{C}, v \mathrm{C}-\mathrm{O}$ & $1270 \mathrm{~s}$ & $1280 \mathrm{~s}$ & 1324 & 1273 & 48.5 & 21.2 \\
\hline 11 & $\beta \mathrm{O}-\mathrm{H}, \beta \mathrm{O}-\mathrm{H}, v \mathrm{C}-\mathrm{H}$ & $1180 \mathrm{~m}$ & - & 1213 & 1166 & 79.4 & 1.6 \\
\hline 12 & $v \mathrm{C}-\mathrm{C}, \beta \mathrm{O}-\mathrm{H}$ & $1130 \mathrm{~ms}$ & $1125 \mathrm{~s}$ & 1207 & 1160 & 136.1 & 1.9 \\
\hline 13 & $v \mathrm{C}-\mathrm{C}, \gamma \mathrm{C}-\mathrm{H}$ & - & $1066 \mathrm{~s}$ & 1082 & 1040 & 2.4 & 10.0 \\
\hline 14 & $v_{\text {as }} \mathrm{C}-\mathrm{O}, \gamma \mathrm{C}-\mathrm{H}$ & - & $854 \mathrm{~m}$ & 869 & 836 & 1.7 & 45.7 \\
\hline 15 & $\gamma \mathrm{C}-\mathrm{H}, \gamma \mathrm{C}-\mathrm{H}$ & $779 \mathrm{w}$ & - & 795 & 764 & 41.5 & 2.6 \\
\hline 16 & $\tau \mathrm{C}-\mathrm{H}$ & $706 \mathrm{w}$ & - & 739 & 710 & 51.2 & 0.6 \\
\hline 17 & $\nu \mathrm{C}-\mathrm{Br}, \tau$-ring, $\gamma \mathrm{O}-\mathrm{H}$ & $648 \mathrm{~m}$ & $652 \mathrm{~ms}$ & 672 & 646 & 5.7 & 8.3 \\
\hline 18 & $\beta \mathrm{C}-\mathrm{H}$ & 480 vs & $485 \mathrm{~m}$ & 501 & 481 & 3.2 & 11.5 \\
\hline 19 & $\nu \mathrm{C}-\mathrm{Br}, \beta$ ring & - & $401 \mathrm{~m}$ & 408 & 392 & 0.9 & 2.7 \\
\hline 20 & $\beta \mathrm{C}-\mathrm{Br}$ & - & $261 \mathrm{~m}$ & 271 & 261 & 0.9 & 6.4 \\
\hline 21 & $\gamma \mathrm{C}-\mathrm{Br}, \gamma \mathrm{C}-\mathrm{C}, \gamma$ ring & - & $205 \mathrm{~m}$ & 208 & 200 & 0.4 & 2.5 \\
\hline 22 & $\tau$ ring & - & $185 \mathrm{~ms}$ & 180 & 173 & 0.1 & 4.6 \\
\hline 23 & $\delta \mathrm{C}-\mathrm{Br}, \delta$-ring & - & $118 \mathrm{w}$ & 123 & 118 & 0.0 & 1.9 \\
\hline 24 & $\delta \mathrm{C}-\mathrm{Br}, \delta$-ring & - & $111 \mathrm{w}$ & 119 & 114 & 0.0 & 0.9 \\
\hline
\end{tabular}

a $\nu$-stretching; $v_{a s}$-asym. stretching; $\beta$-in-plane-bending; $\gamma$-out-of-plane bending; $\tau$-torsion; $\delta$-deformation.

b vs, very strong; s, strong; w, weak; sh, shoulder; ms; medium strong; m, medium.

c With the scale factor of 0.958 for calculated wavenumbers upper than $3000 \mathrm{~cm}^{-1}[15,16]$ and the scale factor of 0.9613 for lower wavenumbers [17].

[10], the corresponding ones in TBBPA were assigned at $261 \mathrm{~cm}^{-1}$ $205 \mathrm{~cm}^{-1}, 118 \mathrm{~cm}^{-1}$ and $111 \mathrm{~cm}^{-1}$, respectively. We propose that the red shift of $\mathrm{C}-\mathrm{Br}$ is ascribed to the further electronic density equalization due to the $\mathrm{p}-\pi$ conjugation between $\mathrm{O}$ atom and the benzene. Moreover, the mode near $1069 \mathrm{~cm}^{-1}$ in the Raman spectrum of BDE-47 [10], showing the contribution of the $\mathrm{C}-\mathrm{Br}$ vibrational mode, could not be observed for TBBPA. The result is consistent with the reported assignments for 3,5-dibromosalicylic acid [19]. The calculated frequencies of $\mathrm{C}-\mathrm{Br}$ vibration presented no evident discrepancy than the ones of BDE-47 [10].

\section{Mulliken charges}

The Mulliken charges at various atoms except $\mathrm{H}$ of TBBPA calculated at the B3LYP/6-31G(d) level were collected in Table 3. As Sudha et al. [23] showed, the substitution of halogen atom and the 
Table 3

Mulliken atomic charge of TBBPA.

\begin{tabular}{lc}
\hline Atom No. & B3LYP/6-31G(d) \\
\hline $\mathrm{Br}_{1}$ & -0.132546 \\
$\mathrm{Br}_{2}$ & -0.090318 \\
$\mathrm{O}_{3}$ & -0.621639 \\
$\mathrm{C}_{4}$ & 0.161388 \\
$\mathrm{C}_{5}$ & -0.212749 \\
$\mathrm{C}_{6}$ & 0.046144 \\
$\mathrm{C}_{7}$ & 0.304043 \\
$\mathrm{C}_{8}$ & 0.043391 \\
$\mathrm{C}_{9}$ & -0.226737 \\
$\mathrm{C}_{10}$ & -0.056571 \\
$\mathrm{C}_{11}$ & -0.460162 \\
$\mathrm{C}_{12}$ & 0.159758 \\
$\mathrm{C}_{13}$ & -0.459229 \\
$\mathrm{C}_{14}$ & -0.206888 \\
$\mathrm{C}_{15}$ & -0.234101 \\
$\mathrm{C}_{16}$ & 0.043822 \\
$\mathrm{C}_{17}$ & 0.044590 \\
$\mathrm{Br}_{18}$ & -0.104422 \\
$\mathrm{C}_{19}$ & 0.304890 \\
$\mathrm{Br}_{20}$ & -0.118513 \\
$\mathrm{O}_{21}$ & -0.623904 \\
\hline
\end{tabular}

hydroxyl group in the aromatic ring lead to the redistribution of electron density. The shift of partial charge from C7(0.304043) and $\mathrm{C} 19(0.304890)$ to $\mathrm{O} 3(-0.621639)$ and $021(-0.623904)$ demonstrated that the conjugation effect between $\mathrm{O}$ and benzene ring.

The four bromine atoms have the higher negative values $(-0.09$ to -0.13 ) owing to the electron withdrawing character. Mulliken population analysis chart of TBBPA was shown in Fig. 4 in Supplementary.

\section{NBO analysis}

By showing the accurate natural Lewis structural picture of model compound, NBO analysis is a powerful tool in understanding various donor-acceptor interactions between the filled and the vacant orbitals of the subsystem [24]. The NBO analysis was performed at B3LYP/6-31G(d) level to elucidate the intra-molecular rehybridization and delocalization of electron density on TBBPA.

For each donor (i) and acceptor (j), the stabilization energy $E(2)$ associated with the delocalization $\mathrm{i} \rightarrow \mathrm{j}$ is estimated as.

$E^{(2)}=\Delta E_{i j}=q_{i} \frac{F(i, j)^{2}}{\varepsilon_{j}-\varepsilon_{i}}$

where $q_{i}$ is the donor orbital occupancy, while $F(i, j)$ is the off diagonal NBO Fock matrix element, and $\varepsilon_{i}$ and $\varepsilon_{j}$ are diagonal elements [24]. The larger of the $E^{(2)}$ value suggests the more intensive interactions between electron-donors and electron-acceptors, and the greater the extent of conjugation of the whole system [25]. From the NBO analysis (Table 4), it was observed that the intermolecular hyperconjugative interactions are mainly formed by the orbital overlap between $\sigma(\mathrm{O}-\mathrm{H}), \sigma^{*}(\mathrm{C}-\mathrm{C}), \pi(\mathrm{C}-\mathrm{C}), \pi^{*}(\mathrm{C}-\mathrm{C})$ bond orbital which result in the intramolecular charge transfer causing stabilization of the whole system. The maximum energy transfer occurred from $\pi^{*}(\mathrm{C}-\mathrm{C})$ to $\pi^{*}(\mathrm{C}-\mathrm{C})$ in the both benzene rings are $115.25-244.01 \mathrm{kcal} / \mathrm{mol}$. The lone pairs of $\mathrm{O} 3$ and 021 have the lower occupancy (1.852 electrons) than the ones of 4 bromine atoms (1.935-1.949 electrons) and seem to be delocalized into neighboring $\mathrm{C} 17-\mathrm{C} 19$ or $\mathrm{C} 7-\mathrm{C} 8$. Compared to the interaction between the $\mathrm{LP}(3) \mathrm{Br}$ and $\pi^{*}(\mathrm{C}-\mathrm{C})\left(E^{(2)}: 8.23-9.73 \mathrm{kcal} / \mathrm{mol}\right)$, the higher $E^{(2)}$ value $(33.65-34.82 \mathrm{kcal} / \mathrm{mol})$ originated from $\operatorname{LP}(2) 0$ to $\pi^{*}$ $(\mathrm{C}-\mathrm{C})$ may contribute to the preferential tendency of debromination to the $\mathrm{C}-\mathrm{O}$ breakage in the transformation.

\section{${ }^{1} \mathrm{H}$ and ${ }^{13} \mathrm{C}$ NMR analysis}

Fig. 5 in Supplementary shows the measured ${ }^{13} \mathrm{C}$ NMR and ${ }^{1} \mathrm{H}$ NMR spectra of TBBPA. The chemical shifts of $\mathrm{C}$ and $\mathrm{H}$ atoms were calculated and compared with the corresponding experimental data, and were shown in Table 5. The correlation analysis of the calculation and experimental data was performed in order to quantify the agreement, and the result was listed in Fig. 6 in Supplementary. As shown in our previous work on BDE-15 [9],

Table 4

Second order perturbation theory analysis of Fock matrix in NBO analysis for TBBPA.

\begin{tabular}{|c|c|c|c|c|c|c|c|c|}
\hline Donor $(i)$ & Type & $\mathrm{ED} / \mathrm{e}$ & Acceptor $(j)$ & Type & $\mathrm{ED} / \mathrm{e}$ & $E(2)^{\mathrm{a}}(\mathrm{kcal} / \mathrm{mol})$ & $E(j)-E(i)^{\text {b }}$ (a.u.) & $F(i, j)^{\mathrm{c}}$ (a.u.) \\
\hline $\mathrm{O} 3-\mathrm{H} 23$ & $\sigma$ & 1.987 & $\mathrm{C} 7-\mathrm{C} 8$ & $\sigma^{*}$ & 0.039 & 5.74 & 1.28 & 0.077 \\
\hline $\mathrm{O} 21-\mathrm{H} 27$ & $\sigma$ & 1.987 & C16-C19 & $\sigma^{*}$ & 0.039 & 5.74 & 1.27 & 0.077 \\
\hline \multirow[t]{2}{*}{$\mathrm{C} 4-\mathrm{C} 9$} & $\pi$ & 1.668 & $\mathrm{C} 5-\mathrm{C} 6$ & $\pi^{*}$ & 0.400 & 22.77 & 0.26 & 0.070 \\
\hline & & & $\mathrm{C} 7-\mathrm{C} 8$ & $\pi^{*}$ & 0.440 & 19.03 & 0.26 & 0.064 \\
\hline \multirow{2}{*}{ C5-C6 } & $\pi$ & 1.978 & C4-C9 & $\pi^{*}$ & 0.352 & 15.19 & 0.31 & 0.062 \\
\hline & & & $\mathrm{C} 7-\mathrm{C} 8$ & $\pi^{*}$ & 0.440 & 21.27 & 0.28 & 0.072 \\
\hline \multirow[t]{2}{*}{$\mathrm{C} 7-\mathrm{C} 8$} & $\pi$ & 1.654 & C4-C9 & $\pi^{*}$ & 0.352 & 21.07 & 0.30 & 0.072 \\
\hline & & & $\mathrm{C} 5-\mathrm{C} 6$ & $\pi^{*}$ & 0.401 & 16.61 & 0.29 & 0.063 \\
\hline \multirow[t]{2}{*}{$\mathrm{C} 12-\mathrm{C} 15$} & $\pi$ & 1.679 & $\mathrm{C} 14-\mathrm{C} 16$ & $\pi^{*}$ & 0.373 & 21.64 & 0.27 & 0.069 \\
\hline & & & C17-C19 & $\pi^{*}$ & 0.442 & 18.86 & 0.26 & 0.064 \\
\hline \multirow[t]{2}{*}{$\mathrm{C} 14-\mathrm{C} 16$} & $\pi$ & 1.720 & C12-C15 & $\pi^{*}$ & 0.349 & 16.07 & 0.30 & 0.063 \\
\hline & & & $\mathrm{C} 17-\mathrm{C} 19$ & $\pi^{*}$ & 0.442 & 21.77 & 0.27 & 0.072 \\
\hline \multirow[t]{2}{*}{ C17-C19 } & $\pi$ & 1.683 & $\mathrm{C} 12-\mathrm{C} 15$ & $\pi^{*}$ & 0.349 & 20.20 & 0.31 & 0.072 \\
\hline & & & $\mathrm{C} 14-\mathrm{C} 16$ & $\pi^{*}$ & 0.373 & 14.90 & 0.30 & 0.060 \\
\hline $\mathrm{Br} 2$ & $\mathrm{LP}(3)$ & 1.936 & $\mathrm{C} 7-\mathrm{C} 8$ & $\pi^{*}$ & 0.440 & 9.73 & 0.29 & 0.053 \\
\hline Br18 & $\mathrm{LP}(3)$ & 1.935 & $\mathrm{C} 14-\mathrm{C} 16$ & $\pi^{*}$ & 0.373 & 9.82 & 0.30 & 0.053 \\
\hline $\mathrm{Br} 1$ & $\mathrm{LP}(3)$ & 1.948 & $\mathrm{C} 5-\mathrm{C} 6$ & $\pi^{*}$ & 0.401 & 8.50 & 0.32 & 0.051 \\
\hline Br20 & $\mathrm{LP}(3)$ & 1.949 & C17-C19 & $\pi^{*}$ & 0.442 & 8.23 & 0.31 & 0.050 \\
\hline $\mathrm{O} 21$ & $\mathrm{LP}(2)$ & 1.852 & & & & 34.84 & 0.32 & 0.103 \\
\hline $\mathrm{O} 3$ & $\mathrm{LP}(2)$ & 1.852 & $\mathrm{C} 7-\mathrm{C} 8$ & $\pi^{*}$ & 0.440 & 33.65 & 0.33 & 0.101 \\
\hline C5-C6 & $\pi^{*}$ & 0.400 & C4-C9 & $\pi^{*}$ & 0.352 & 158.93 & 0.02 & 0.084 \\
\hline $\mathrm{C} 7-\mathrm{C} 8$ & $\pi^{*}$ & 0.440 & & & & 115.25 & 0.03 & 0.079 \\
\hline C14-C16 & $\pi^{*}$ & 0.373 & C12-C15 & $\pi^{*}$ & 0.349 & 223.52 & 0.01 & 0.084 \\
\hline C17-C19 & $\pi^{*}$ & 0.442 & $\mathrm{C} 14-\mathrm{C} 16$ & $\pi^{*}$ & 0.373 & 244.01 & 0.01 & 0.081 \\
\hline
\end{tabular}

\footnotetext{
${ }^{\text {a }} E(2)$ means energy of hyperconjugative interactions (stabilization energy).

b Energy difference between donor and acceptor $i$ and $j$ NBO orbitals.

c $F(i, j)$ is the Fock matrix element between $i$ and $j$ NBO orbitals.
} 
Table 5

Comparison of theoretical and experimental results of NMR chemical shifts of TBBPA.

\begin{tabular}{|c|c|c|}
\hline \multirow[t]{2}{*}{ Method } & \multicolumn{2}{|l|}{ Atom type } \\
\hline & $\delta_{\mathrm{C}}(\mathrm{ppm})$ & $\delta_{\mathrm{H}}(\mathrm{ppm})$ \\
\hline Experimental & $147.762,144.610,134.473,127.862,110.455,40.570,28.147$ & $1.528,7.257$ \\
\hline Calculated by B3LYP/6-31G(d) & $142.149,135.608,124.928,111.489,44.754,30.955$ & $1.601,5.026,6.847$ \\
\hline Correlation analysis & $y^{\mathrm{a}}=0.977 x^{\mathrm{b}}+1.918 r^{2}=0.999$ & \\
\hline
\end{tabular}

Table 6

Main excitation energy $(E)$ and oscillator strength $\left(f_{\text {osc }}\right)$ calculated at the TD-B3LYP/6$31 \mathrm{G}(\mathrm{d})$ level for TBBPA

\begin{tabular}{lllll}
\hline States & $E(\mathrm{eV})$ & Transition & Main configuration & $f_{\text {osc }}$ \\
\hline $\mathrm{S}_{3}$ & 4.68 & HOMO $\rightarrow$ LUMO & $\pi \rightarrow \pi^{*}$ & 0.0833 \\
$\mathrm{~S}_{24}$ & 6.05 & HOMO-1 $\rightarrow$ LUMO +5 & $\pi \rightarrow \pi^{*}$ & 0.5221 \\
$\mathrm{~S}_{27}$ & 6.16 & HOMO-2 $\rightarrow$ LUMO +5 & $\pi \rightarrow \pi^{*}$ & 0.1898 \\
\hline
\end{tabular}

the results obtained on the $6-31 \mathrm{G}(\mathrm{d})$ level proved good agreement with the experimental data $\left(r^{2}=0.999\right)$. The discrepancy is probably ascribed to the exclusion of solvent effect in the calculations.

As presented in Fig. 5 in Supplementary, the peak with $\delta_{\mathrm{H}}$ of $4.905 \mathrm{ppm}$ was supposed to be related with the proton of the solvent $\mathrm{MeOH}-\mathrm{d} 4$. The calculated chemical shift of $5.026 \mathrm{ppm}$ was ascribed to $\mathrm{H} 28-\mathrm{H} 33$ atoms. The overlap signal and limited NMR spectroscopic resolution probably lead to the absence of the peak in Fig. 5 in Supplementary. Normally, the protons on phenyl ring are expected to yield NMR signals in the $\delta_{\mathrm{H}}$ region of $6-8.5 \mathrm{ppm}$ [26]. In the experimental spectrum, the presence of one peak with $\delta_{\mathrm{H}}$ of $7.257 \mathrm{ppm}$ showed that the four protons $(\mathrm{H} 22, \mathrm{H} 24, \mathrm{H} 25$, $\mathrm{H} 26$ ) of the aromatic benzene are identical.

The ${ }^{13} \mathrm{C}$ NMR spectrum shows 6 separate signals for all 15 carbons present in TBBPA. Normally, the aromatic and the saturated carbon in ${ }^{13} \mathrm{C}$ NMR spectra usually locate in the $\delta_{\mathrm{C}}$ range of 110 $160 \mathrm{ppm}$ and $5-55 \mathrm{ppm}$, respectively [19]. The peaks at $44.754 \mathrm{ppm}$ and $30.955 \mathrm{ppm}$ are assigned to C10 and C11(13). As shown in BDE-15 [9], the conjugation arising from the phenyl ring and the lone-pair electron of $\mathrm{O} 21$ and $\mathrm{O} 3$ contributes to the $\mathrm{C} 7(19)$, generating the signal at $142.149 \mathrm{ppm}$ in present work. We can expect that the interaction between the C7(19) and the adjacent bromine atoms in the real test probably contributes to the splitting of the line around $140 \mathrm{ppm}$ in the observed spectrum. As for this, the average value of this signal (146.186 ppm) was chosen for linear fit. The signal at $110.455 \mathrm{ppm}$ in the spectrum is assigned to the C $6(8,16,17)$ on account of the strong electronegative property of the adjacent $\mathrm{Br}$ atoms. Thus, the peak at $118.2 \mathrm{ppm}$ was assigned to $\mathrm{C} 5(9,14,15)$ because of the impact of meta- $\mathrm{Br}$ atoms. The relative high chemical shifts at $134.473 \mathrm{ppm}$ was ascribed to $\mathrm{C} 4(12)$.

\section{HOMO-LUMO and electronic transition adsorption analysis}

The highest occupied molecular orbital (HOMO) and the lowest occupied molecular orbital (LUMO) represent the ability to denote or accept an electron [24,27]. The electronic transition corresponding to the transition from the ground to the excited state was listed in Table 6.

The TDDFT calculation results were listed in Fig. 7 in Supplementary. To better understand the ascription of adsorptions, isosurfaces of the main related orbitals were depicted in Fig. 8 in Supplementary. The electronic excitation coefficients indicate that the orbital excited from $S_{0}-S_{3}$ transition has its main contribution from transition from the HOMO to LUMO orbital with $\pi-\pi^{*}$ character $(f=0.0833)$. As can be appreciated from its isosurfaces in Fig. 8 in Supplementary, the orbital excited from $\mathrm{S}_{0}-\mathrm{S}_{24}$ transition $(f=0.5221)$ and $S_{0}-S_{27}(f=0.1898)$ are mainly described by excitation out of the HOMO-1 into the LUMO+5 orbital and HOMO-2 into the LUMO +5 , respectively. Both the excitation exhibit clear $\pi-\pi^{*}$ character localized on the benzene rings.

\section{Conclusions}

The optimized geometry of TPPBA was obtained by using density functional B3LYP method with the 6-31G(d) basis set. Both experimental and theoretical study on the FT-IR, Raman, ${ }^{1} \mathrm{H}$ NMR, and ${ }^{13} \mathrm{C}$ NMR spectra of TBBPA were carried out. The calculated $A C_{4}-C_{10}-C_{13}-C_{11}\left(118.2^{\circ}\right)$ clearly indicates a typical tetrahedral structure constituted by the atoms of $\mathrm{C} 4, \mathrm{C} 10, \mathrm{C} 11, \mathrm{C} 12, \mathrm{C} 13$. The scaled vibrational wavenumbers, IR intensities, Raman activities showed good agreement with the experimental data. Comparative analysis to corresponding vibrational properties for PBDEs showed that the red shift of $\mathrm{C}-\mathrm{Br}$ vibration is probably ascribed to the further electronic density equalization due to the $p-\pi$ conjugation between $\mathrm{O}$ atom and the benzene. The NMR calculation results demonstrated good agreement with the experimental values $\left(r^{2}=0.999\right)$.

The NBO analysis result demonstrated that the intermolecular hyperconjugative interactions are mainly formed by the orbital overlap between $\sigma(\mathrm{O}-\mathrm{H}), \sigma^{*}(\mathrm{C}-\mathrm{C}), \pi(\mathrm{C}-\mathrm{C}), \pi^{*}(\mathrm{C}-\mathrm{C})$ bond orbital.

The lower $E^{(2)}$ value $(33.65-34.82 \mathrm{kcal} / \mathrm{mol})$ originated from $\mathrm{LP}(3) \mathrm{Br}$ and $\pi^{*}(\mathrm{C}-\mathrm{C})\left(E^{(2)}: 8.23-9.73 \mathrm{kcal} / \mathrm{mol}\right)$ leads to the preferential tendency of $\mathrm{C}-\mathrm{Br}$ breakage in the transformation. The TDDFT computation results showed that all the main excitation exhibit $\pi$ $\pi^{*}$ character localized on the benzene rings.

\section{Appendix A. Supplementary material}

Supplementary data associated with this article can be found, in the online version, at http://dx.doi.org/10.1016/j.saa.2012.12.004.

\section{References}

[1] M. Grabda, S. Oleszek-Kudlak, E. Shibata, T. Nakamur, J. Mol. Struct. (THEOCHEM) 822 (2007) 38-44.

[2] J. Legler, Chemosphere 73 (2008) 216-222.

[3] M. Abb, B. Stahl, W. Lorenz, Chemosphere 85 (2011) 1657-1663.

[4] http://www.china-pops.net/ypnew_view.asp?id=3236.

[5] J. Xu, W. Meng, Y. Zhang, L. Li, C. Guo, Appl. Catal., B 107 (2011) 355-362.

[6] J.R. Nyholm, C. Lundberg, P.L. Andersson, Environ. Pollut. 158 (2010) 22352240.

[7] S. Luo, S.G. Yang, X.D. Wang, C. Sun, Chemosphere 79 (2010) 67-678.

[8] S. Kovarich, E. Pap, P. Gramatica, J. Hazard. Mater. 190 (2011) 106-112.

[9] S.S. Qiu, X.H. Tan, K. Wu, A.Q. Zhang, S. Han, L.S. Wang, Spectrochim. Acta A76 (2010) 429-434.

[10] S.S. Qiu, L. Liu, X. Jin, A.Q. Zhang, K. Wu, L.S. Wang, Spectrochim. Acta A77 (2010) 572-578.

[11] M.J. Frisch, G.W. Trucks, H.B. Schlegel, G.E. Scuseria, M.A. Robb, J.R. Cheeseman, J.A. Montgomery Jr., T. Vreven, K.N. Kudin, J.C. Burant, J.M. Millam, S.S. Iyengar, J. Tomasi, V. Barone, B. Mennucci, M. Cossi, G. Scalmani, N. Rega, G.A. Petersson, H. Nakatsuji, M. Hada, M. Ehara, K. Toyota, R. Fukuda, J. Hasegawa, M. Ishida, T. Nakajima, Y. Honda, O. Kitao, H. Nakai, M. Klene, X. Li, J.E. Knox, H.P. Hratchian, J.B. Cross, V. Bakken, C. Adamo, J. Jaramillo, R. Gomperts, R.E. Stratmann, O. Yazyev, A.J. Austin, R. Cammi, C. Pomelli, J.W. Ochterski, P.Y. 
Ayala, K. Morokuma, G.A. Voth, P. Salvator, J.J. Dannenberg, V.G. Zakrzewski, S. Dapprich, A.D. Daniels, M.C. Strain, O. Farkas, D.K. Malick, A.D. Rabuck, K. Raghavachari, J.B. Foresman, J.V. Ortiz, Q. Cui, A.G. Baboul, S. Clifford, J. Ciomslowski, B.B. Stefanov, G. Liu, A. Liashenko, P. Piskorz, I. Komaromi, R.L. Martin, D.J. Fox, T. Keith, M.A. Al-Laham, CY. Peng, A. Nanayakkara, M.Challacombe, P.M.W. Gill, B. Johnson, W. Chen, M.W. Wong, C. Gonzalez, J.A. Pople, Gaussian 03, D.01, Gaussian, Inc., Wallingford CT, 2004.

[12] R. Dennington II, T. Keith, J. Millam, GaussView, Version 4.1, Semichem, Inc. Shawnee Mission, KS, 2007.

[13] J. Eriksson, L. Eriksson, Acta Cryst. C57 (2001) 1308-1312.

[14] P.M. Wojciechowski, D. Michalska, Spectrochim. Acta A 68 (2007) 948-955.

[15] D. Michalska, W. Zierkiewicz, D.C. Bienko, W. Wojciechowski, J. Phys. Chem. A 105 (2001) 8734-8739.

[16] A.P. Scott, L. Radom, J. Phys. Chem. 100 (1996) 16502-16513.

[17] G. Varsanyi, Assignments of Vibrational Spectra of 700 Benzene Derivatives, Wiley, New York, 1974.
[18] N. Sundaraganesan, J. Karpagam, S. Sebastian, J.P. Cornard, Spectrochim. Acta A73 (2009) 11-19.

[19] V. Balachandran, S. Rajeswari, S. Lalitha, J. Mol. Struct. 1007 (2012) 63-73.

[20] M. Silverstein, G. Clayton Basseler, C. Morill, Spectrometric Identification of Organic Compounds, Wiley, New York, 1981.

[21] E.F. Mooney, Spectrochim. Acta 20 (1964) 1021-1032.

[22] E.F. Mooney, Spectrochim. Acta 19 (1963) 877-887.

[23] S. Sudha, N. Sundaraganesan, M. Kurt, M. Cinar, M. Karabacak, J. Mol. Struct. 985 (2011) 148-156.

[24] S. Subashchandrabose, A.R. Krishnan, H. Saleem, V. Thanikachalam, G. Manikandan, Y. Erdogdu, J. Mol. Struct. 981 (2010) 59-70.

[25] S. Sebastian, N. Sundaragnesan, Spectrochim. Acta A75 (2010) 941-952.

[26] L.D.S. Yadav, Organic Spectroscopy, second ed., Anamaya Publisheras, New Delhi, 2007.

[27] S. Gunasekaran, R.A. Balaji, S. Kumerasan, G. Anand, S. Srinivasan, Can. J. Anal. Sci. Spectrosc. 53 (2008) 149-161. 